\title{
The antibiotic revolution should be more focused
}

In medical history texts the second half of the twentieth century is often referred to as the 'antibiotic revolution'. As Macfarlane and Worboys described in their wonderful article on management of acute bronchitis between 1940 and 1970, the appearance of these 'wonder drugs' on the market not only helped GPs to cope with their increasing workload, but also caused a remarkable shift in doctors' opinions about the aetiology of infectious diseases like bronchitis.

Before antibiotics were available, bronchitis was regarded as a self-limiting inconvenient illness caused by changes in the environment of the patient, like sudden cold, and or the patient's susceptibility. Bacterial infection was regarded as a secondary complication. But with the emergence of penicillin, the assumption that all chest conditions and other respiratory tract symptoms were primarily caused by bacteria that should be killed was broadly accepted.

In spite of numerous good studies on the limited effects of antibiotics, this legacy of assumed bacterial infections that should be treated, along with the pressure of busy clinics continue to be driving forces of prescribing in general practice. Over-treatment of presumed infectious conditions, mainly respiratory illnesses, is still present in all Western countries. In 2006, a study in the Netherlands, where antibiotic use is very low compared to other countries, showed that almost $50 \%$ of patients with chest infections got antimicrobial treatment, while only $10 \%$ had an indication according to current guidelines. ${ }^{2}$

Because this overuse of antibiotics causes frequent side effects (in around $20 \%$ of users) and is clearly linked with antimicrobial resistance, ${ }^{3,4}$ many campaigns have been initiated to rationalise antibiotic use in primary care. In Belgium, France, and the UK, such public campaigns were organised and seem to be successful. ${ }^{5-7}$ Meropol et $a /^{8}$ show in their paper in this issue of the BJGP that this decrease in antibiotic use in the UK is both seen in adults and children and is not accompanied with a rise in the use of newer broad spectrum agents, as has been seen in the US. In France the campaign was combined with interventions aimed at physicians, including the publication of guidelines, academic detailing (personal visits and education at the practice), and encouraging GPs to use near-patient tests such as the rapid strep test, a throat swab to detect streptococci. ${ }^{6}$ In some countries in northern Europe with lower antibiotic use than France and Belgium, no public campaigns were done, interventions were focused on healthcare personnel, and these projects also showed relevant effects. ${ }^{9-11}$

Although the effects of these public campaigns and primary care projects are often clear and to be applauded, they are also not yet sufficient. Three notions should be taken into account when developing future strategies.

First, we need to realise that different approaches will be necessary in different countries and even regions within countries. Wang et al show in their paper that even within England large variation in antibiotic use in different parts of the country can be seen. ${ }^{12}$ To enable tailored interventions, more detailed information on antibiotic use in the different countries and regions within countries is needed.

Results of large European studies in primary care are now available and provide us with important quantitative and qualitative background information..$^{4,13}$ The European Centre for Disease Prevention and Control (ECDC) recognises the importance of regional or national differentiation of strategies towards a more prudent use of antibiotics, by supporting national contact persons and organisations to enable tailored activities per country. ${ }^{14}$ Each year the European Antibiotic Awareness Day is organised by ECDC and this year, on November 18, the focus will be on primary care.
Second, the instruments to improve our handling of infectious diseases and antibiotic prescription habits should be simple, feasible, and sustainable. Two papers in this issue of the BJGP provide interesting information on this. Moore et al show us that there is a subgroup of patients who visit us frequently and get antibiotics regularly. ${ }^{15}$ Their reconsultation behaviour was reduced by giving them either no antibiotic or, even better, a delayed prescription. The authors point out that giving these patients responsibility for their own treatment apparently helps them to consult less frequently in the future. This is a likely and interesting explanation. Their suggestion that delayed prescription for lower respiratory tract infections (LRTIs) is perhaps to be preferred over no prescription is, however, debatable. In an article on the effects of the use of a nearpatient C-reactive protein (CRP) tests and communication skills, Cals et al showed that using both CRP and sufficient and structured communication skills in daily practice could reduce antibiotic use in $23 \%$ of patients with LRTI. ${ }^{16}$ Treatment was thus targeted to patients with a more serious infection. Although the strategy of delayed prescribing showed relevant reductions in antibiotic use in some studies, it is uncertain whether improvements in antibiotic use, like those in the Cals et al trial, can be established by delayed prescription strategies. This discussion again shows that different settings and countries perhaps need different approaches.

In their paper in this issue of the BJGP, Cals et $a /^{17}$ analysed determinants of reconsultation using data from their earlier trial, ${ }^{16}$ and saw that reconsultation within 1 month was related to severity of symptoms and anxiety of patients, but not to receiving no antibiotics initially. They conclude that discussing concerns and expectations of patients and informing them of the natural course of an uncomplicated LRTI might reduce 
reconsultation rates. This is undoubtedly true, but their assumption would have had more credibility if they could have shown that the patients with whom structured communication skills were used did in fact reconsult less in their study.

The third important notion to be mentioned here is that, although the body of knowledge on aetiology, diagnosis, and treatment and prognosis of infectious diseases and their management in primary care is growing, there are still numerous gaps in our insights on these very frequent illnesses. Who is at risk for complications and how can we prevent an abnormal and serious course of infectious diseases? The study of Vinogradova et al found some potentially new risk factors for pneumonia in primary care patients. ${ }^{18}$ Dementia and stroke were already identified before as risk factors, ${ }^{19}$ but thanks to their large sample size Vinogradova et al were also able to identify less frequent risk factors, such as Parkinson's disease and rheumatoid arthritis.

If confirmed in other studies and if these high risk groups can be shown to benefit from certain interventions, information like this will, in the future, help GPs to target their treatments better and to clarify whom to treat and in whom to refrain. That is because our mission is not to prescribe as few antibiotics as possible, but to identify that small group of patients who really need antimicrobial treatment and to explain, reassure, and educate the large group of patients who don't. The antibiotic revolution should be more focused.

\section{Theo JM Verheij,}

Julius Centre for Health Sciences and Primary

Care, University Medical Centre Utrecht,

Utrecht, The Netherlands.

\section{Provenance}

Commissioned; not peer reviewed.

\section{REFERENCES}

1. Macfarlane JT, Worboys M. The changing management of acute bronchitis in Britain, 1940-1970: the impact of antibiotics. Med Hist 2008; 52(1): 47-72.

2. Akkerman AE, Kuyvenhoven MM, van der Wouden JC, Verheij TJ. Determinants of antibiotic overprescribing in respiratory tract infections in general practice. J Antimicrob Chemother 2005; 56(5): 930-936.

3. Malhotra-Kumar S, Lammens C, Coenen S, et al. Effect of azithromycin and clarithromycin therapy on pharyngeal carriage of macrolide-resistant streptococci in healthy volunteers: a randomised, double-blind, placebo-controlled study. Lancet 2007; 369(9560): 482-490.

4. Goossens H, Ferech M, Vander Stichele R, et al. Outpatient antibiotic use in Europe and association with resistance: a cross-national database study. Lance 2005; 365(9459): 579-587.

5. Goossens H, Guillemot D, Ferech M, et al. National campaigns to improve antibiotic use. Eur J Clin Pharmacol 2006; 62(5): 373-379.

6. Sabuncu E, David J, Bernède-Bauduin C, et al. Significant reduction of antibiotic use in the community after a nationwide campaign in France, 2002-2007. PLoS Med 2009; 6(6): el000084.

7. Lambert MF, Masters GA, Brent SL. Can mass media campaigns change antimicrobial prescribing? A regional evaluation study. J Antimicrob Chemother 2007; 59(3): 537-543.

8. Meropol SB, Chen Z, Metlay JP. Reduced antibiotic prescribing for acute respiratory infections in adults and children. Br J Gen Pract 2009; DOI: 10.3399/bjgp09X472610

9. Welschen I, Kuyvenhoven MM, Hoes AW, Verheij TJ Effectiveness of a multiple intervention to reduce antibiotic prescribing for respiratory tract symptoms in primary care: randomised controlled trial. BMJ 2004; 329(7463): 431.

10. Mölstad S, Erntell M, Hanberger H, et al. Sustained reduction of antibiotic use and low bacterial resistance: 10-year follow-up of the Swedish Strama programme. Lancet Infect Dis 2008; 8(2): 125-132.

11. Rautakorpi UM, Huikko S, Honkanen P. The Antimicrobial Treatment Strategies (MIKSTRA) program: a 5-year follow-up of infection-specific antibiotic use in primary health care and the effect of implementation of treatment guidelines. Clin Infect Dis 2006; 42(9): 1221-1230.

12. Wang KY, Seed P, Schofield P, et al. Which practices are high antibiotic prescribers? A cross-sectional analysis. Br J Gen Pract 2009; DOI: 10.3399/bjgp09X472593.

13. Butler CC, Hood K, Verheij T, et al. Variation in antibiotic prescribing and its impact on recovery in patients with acute cough in primary care: prospective study in 13 countries. BMJ 2009; 338: b2242. doi: 10.1136/bmj.b2242.

14. Earnshaw S, Monnet DL, Duncan B, et al. European Antibiotic Awareness Day, 2008 - the first Europewide public information campaign on prudent antibiotic use: methods and survey of activities in participating countries. Euro Surveill 2009; 14(30): 19280.

15. Moore M, Little P, Rumsby K, et al. Effect of antibiotic prescribing strategies and an information leaflet on longer-term reconsultation for acute lower respiratory tract infection. Br J Gen Pract 2009; 59(567): 728-734.

16. Cals JW, Butler CC, Hopstaken RM, et al. Effect of point of care testing for $\mathrm{C}$ reactive protein and training in communication skills on antibiotic use in lower respiratory tract infections: cluster randomised trial. BMJ 2009; 338: b1374. doi: 10.1136/bmj.b1374.

17. Cals JWL, Hood K, Aaftink N, et al. Predictors of patient-initiated reconsultation for lower respiratory tract infections in general practice. Br I Gen Pract 2009; 59(567): 761-764.

18. Vinogradova Y, Hippisley-Cox J, Coupland C. Identification of new risk factors for pneumonia: population-based case-control study. Br J Gen Pract 2009; DOI: 10.3399/bjgp09X472629.

19. Sliedrecht A, den Elzen WP, Verheij TJ, et al. Incidence and predictive factors of lower respiratory tract infections among the very elderly in the general population. The Leiden 85-plus Study. Thorax 2008; 63(9): 817-822.

DOI: 10.3399/bjgp09X472557

\section{ADDRESS FOR CORRESPONDENCE}

\section{TJM Verheij}

Julius Centre for Health Sciences and Primary Care, University Medical Centre Utrecht, PO Box 85500, 3508 AG Utrecht, The Netherlands. E-mail: T.J.M.Verheij@umcutrecht.nl 